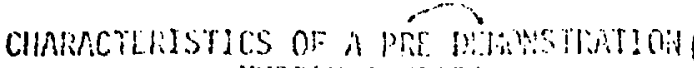
FUS IO:" DEL'ICL"

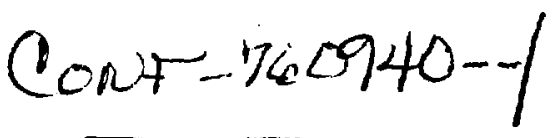

a co:tian e of this a itive, the publisher er i i nl d..knuwidges the U.S. Gevemment's tht to rotain a non - excluaive, reyalty of ho conse in and to any cesuright coverine the ticle:
D. G. Honkest

Oak Ridge National Laboratory

Oak Ridwe, Tomnessee 37830

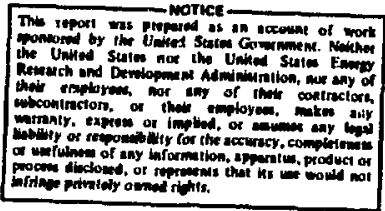

MBSTRACT

Low beta reactor system studies have show that criteria necessitated by the physics lead to difricult engincering problcils. The low pover density pioduced in these systoms also results in large reactors and hakes the question of econonic

$\rightarrow$ viability a serious one. It is clear that if higher pressure plasmas can be confined and operated, many of these problems cuuld be alleviated. The incentives for high plasma density as a means of achieving higher pressuros are discussed. The possible methods of achioving high density are oul ined wili particular attention to the high beta approaches. The require. ments with are imposed on thr reactor by using the flux-consenving tokatibis concept are describeck.

The characteristics of a predemonstration fusion device Which can test the necessary aspects of such a system are deveroped. The plastia size required to attain ignition is found to be relatively smatl provided other criteria can be saifsicd. These criterie are described and the tochrology developisnts and operating proccdures required by them are given. The dymatic behavion and parmotens: of the reference systein during the opereting cycle are also outined.

\footnotetext{
* Research sponsored by the Energy Rosearch and Developncht frininistwiation under contrac with Union Carbife Comporatisin.

Hexom Nuctere Co., Inc.
} 
The power density produced in a reactor plasma depends on the density and temperature of the fucl ions burned. In the $c_{\text {sse }}^{0}$ of a deuterium-iritiun fueled system, this quantity is given by $N_{D} \|_{T}<\sigma v>Q_{F}$. Tokamak reactors will have to operate under ignition conditions to attain economic viability. This requirement imposes parametric constraints on the contaiment system since ignition depends on density, tomperature, and energy confinement time. The energy confinement time in turn depends on ciher variables, but at present - this dependence is nit known. There are indications, however, that confinement time will scale favorably with an increase in density. This result: is suggested both by experinents and by theoretical analyses. Thus from several points of vien there are incentives to operate the reactor plasma at high density.

Several approaches for achieving high density are envisioned. A method which requires a moderate magnetic field (or high beta) is desirable for economic reasons. This may be possible using the concept of a flux-conserving tokamak. (1) lioncircular plasmas may offer a means to high density. (2) Finally, high magnetic fie?ds. (or low beta) may be necessary. ${ }^{(3)}$ In this paper a reference system winch includes a moderate magnetic field, a moderately elongated plasma, and high beta will be developed. Since the operating temperature of the plasma will be in the range of reactor interest, i.e.s $\approx 10-15 \mathrm{keV}$, high beta implies high density and vice versa in this discussion. 
High beta (density) imposes constraints on the design and operation of the system. For example, stable-high beta plasme equilibria must $\because .6 \mathrm{~s}$

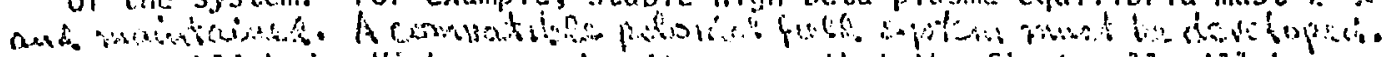
A be established. High power density means that the first wall will be subjected to high neutron fluxes $\left(>1 \mathrm{mil} / \mathrm{m}^{2}\right)$ as well as a high thermal flus. The breakdom and current rise phases of start-up may require high voltages when increased filling pressures are used. Supplemental heating using neutral beams may be difficuit due to the beam energies required to achieve adequate bean particle penetration. Finally, impuriog iy ty and burn product eefects in a dense plasma must be eaamined. In some cases technolngical developments may be needed to meet design criteria while in other cases it may be possible to develop operating poocedures which provide the desired solutions. Specific features of t!nis type are discussed beloli.

\section{SYSTEM HODELING}

There are many ways to simulate the detailed energy balance processes in a tokamak. In the present work the same nodel used previously in the ORN1. Experiment1 Power Reactor Design Sfudy ${ }^{(4)}$ has been adopted, and the impact of high density has been assessed. The timp-dependent

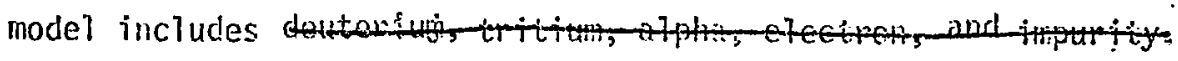

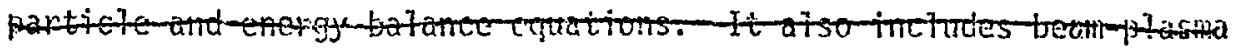

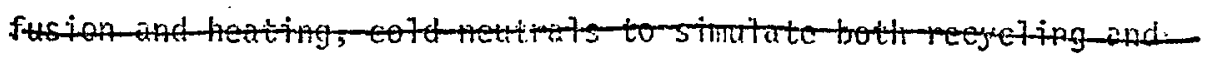
fueling, the effets of impurities on Pseudoclassical, neoclassical, and dissipative trapped partic $l_{e}$ mode

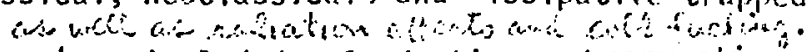
scaling lawsiare irotuded. Conduction and convection times are functions of plasma collisionality. 


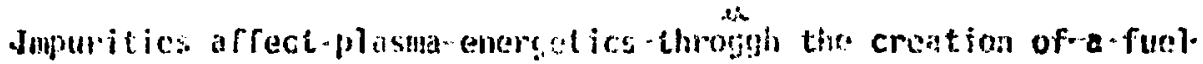

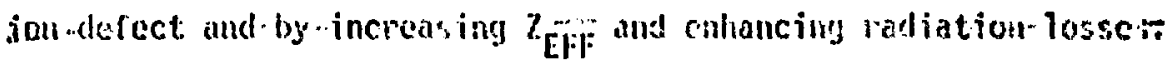
The sources of high-z (ivon) and low-z (carbon) inpurities are tue bits. to.sputtering of the wall by ducterons, tritons, alphas, and inpurities as weth as by charge-exchange neutrats and meutrons protuced-im .the plasma...

Figure 1 shows the phastid racius required for igntion as a function of temperature. The density is $2 \times 10^{20} \mathrm{Ba}^{-3}$, the plasma cargigation (lieight to width ratio) is 1.6 , and the axis magnetic - field, ro three cases $j$ shown. The minimum size for ignition occurs at about $\mathrm{T}=13 \mathrm{keV}$. Below this tenperriture, the he required for ignition increases sharply and an increase in size is necessary to attain it. Above $13 \mathrm{keV}$, trapped ion made transpont ( $\mathrm{kr} \propto \beta^{2} r^{-11 / 2}$ ) dominates the scaling and un increase in plasm size again is reguired. The neutron wall loadings associated bith various opcrating cemperatures are also given. Note that at $N=2 \times 10^{20} \mathrm{nt}^{-3}, \gamma=13 \mathrm{kev}$, and $B_{T}=4.5 \mathrm{~T}$, the wall rowing exceeds $3 \mathrm{kt} / \mathrm{m}^{2}$, and the plasm? radius necessary for ignition is $1.25 \mathrm{~m}$. Hith a field strength of $6.5 \mathrm{~T}$, the size requiced is reduced to $21 \mathrm{~mm}$ and the wall loading is $22.5 \mathrm{~mW} / \mathrm{m}^{2}$.

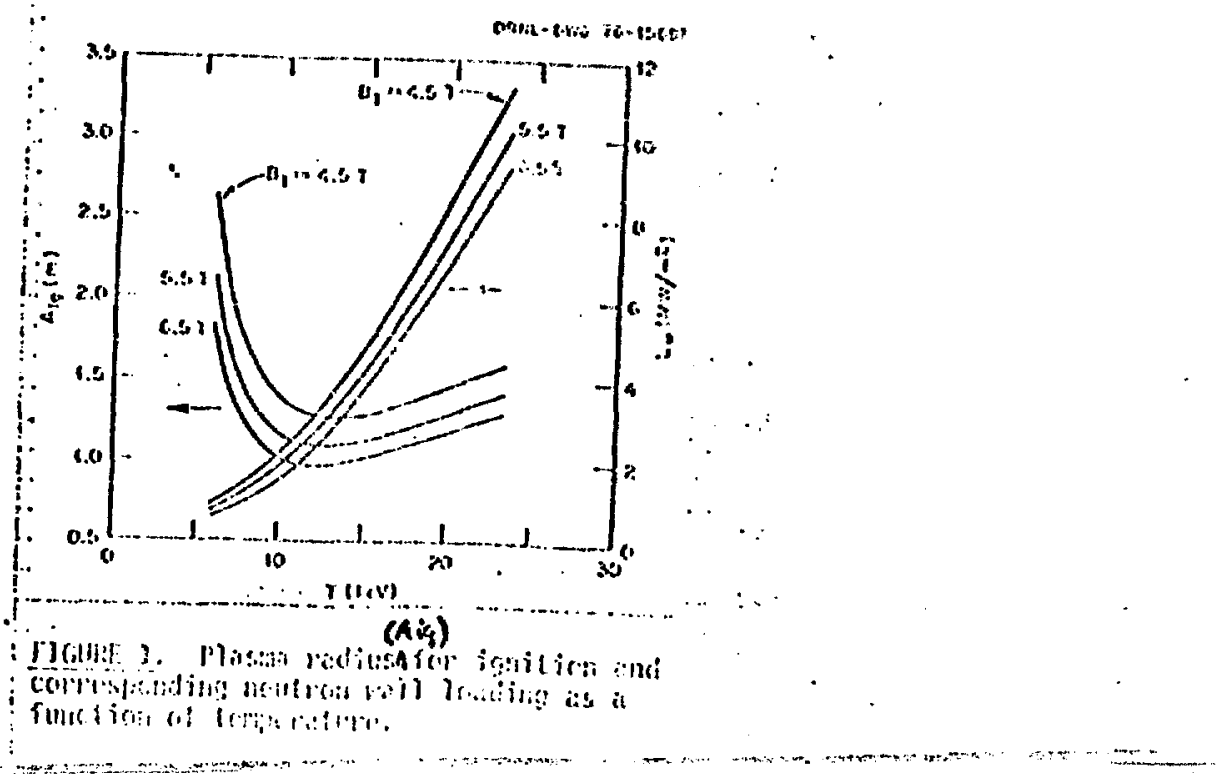




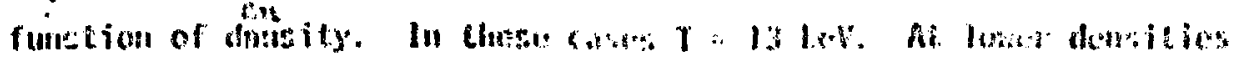

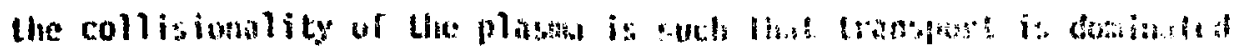

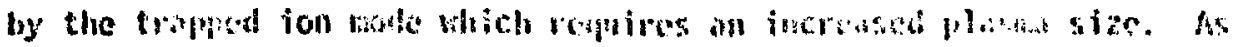

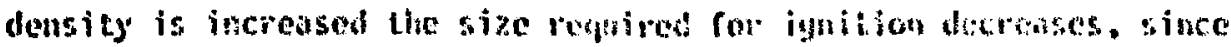

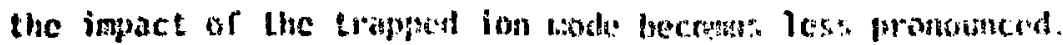

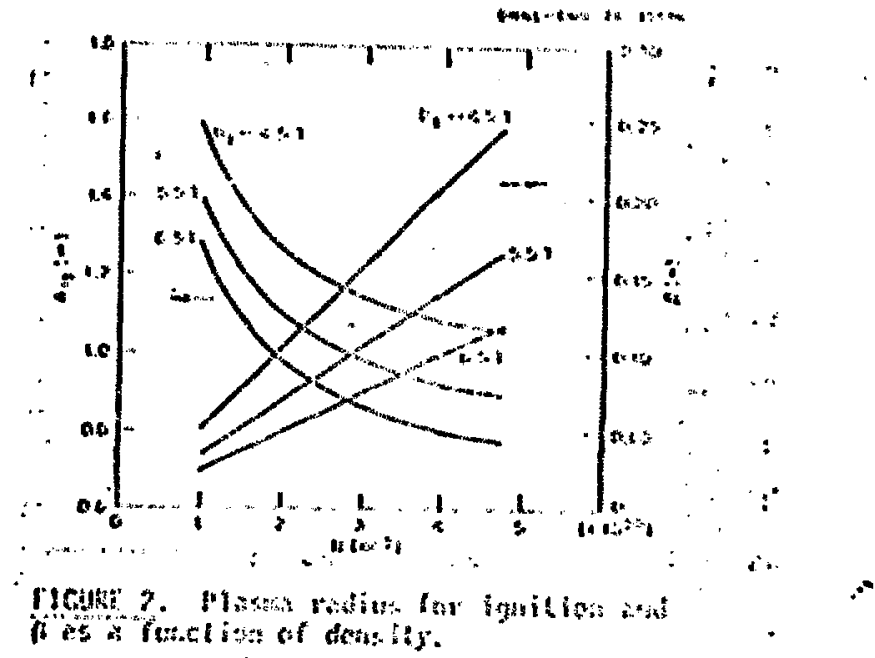

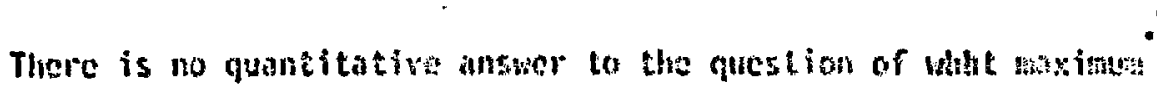
density is icceptable. Mso, thorecical wor: (5) suggests lhat

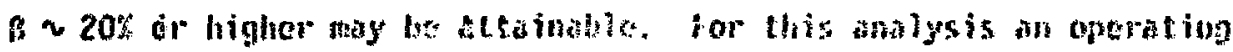

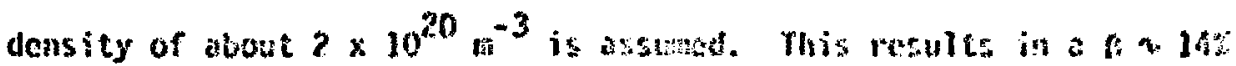

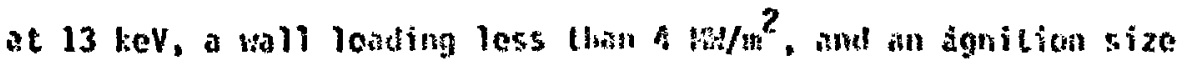

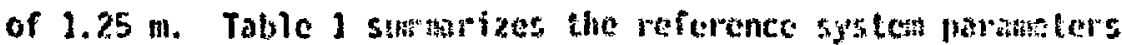

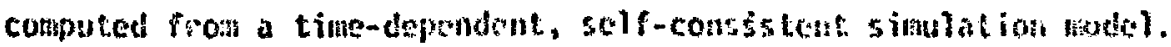

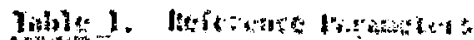

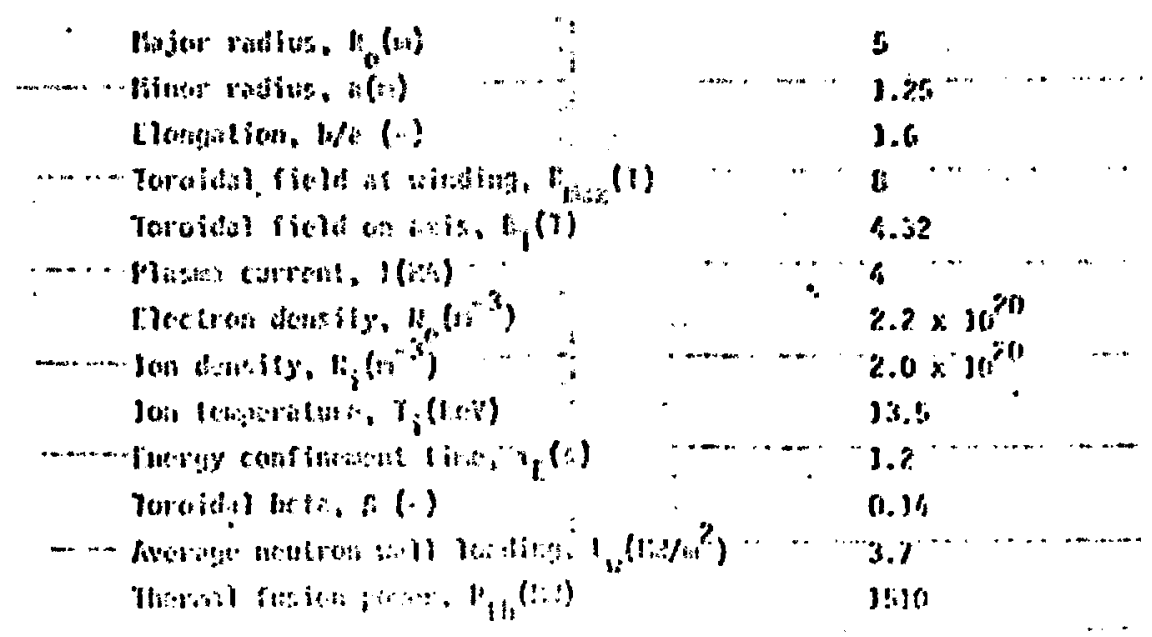




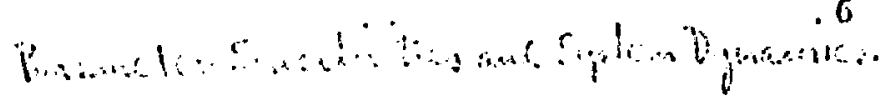

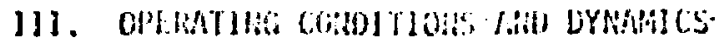

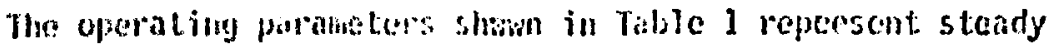
stald conditins. Since the model used includes the trapped ion mode ware $\mathrm{HT}_{\mathrm{E}}$ " $\mathrm{H}^{2} \mathrm{~T}^{-11 / 2}$, the temperalure increases to the point where the energy lass rate chats the liedting sate due to themonuclear alphe particles and a steady state is chiceved. Figure 3 show tic ${ }^{*} \mathrm{~T}_{\mathrm{e}}$ for three differant values of mognetic fielda.

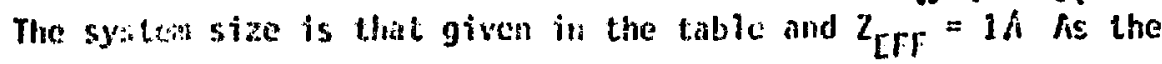

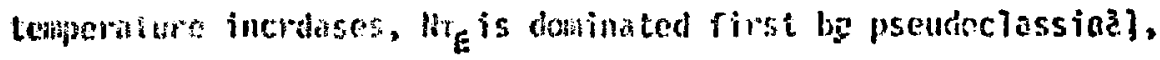
thon by trapped electron moste, and fimlly by trapped ion mode

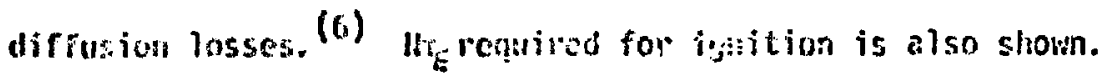

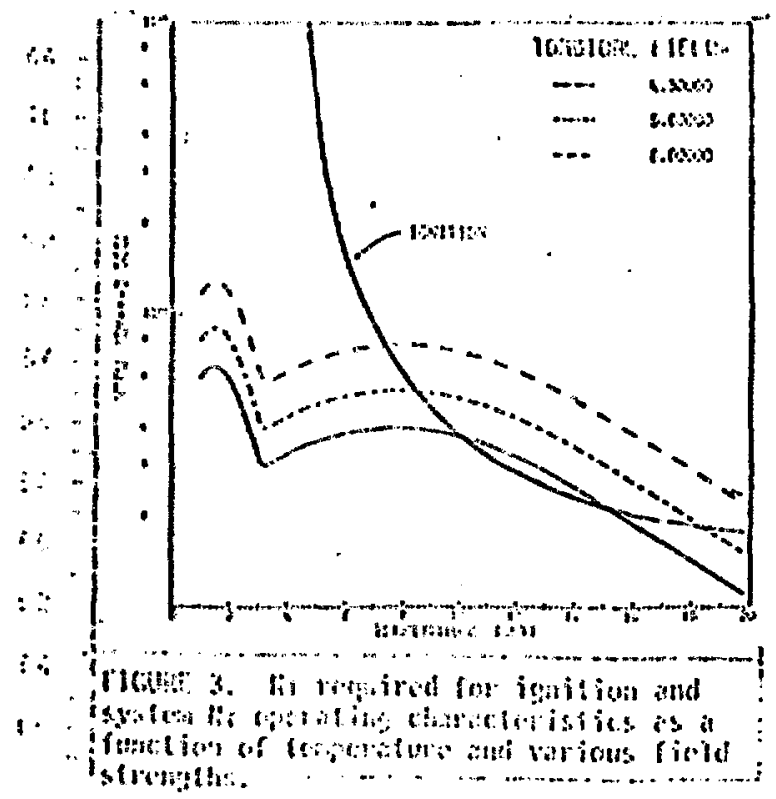

For cxaple, whise when $B_{.}=4.3 \mathrm{~T}$ ignition is attained at $10 \mathrm{keV}$, a thermet cxcursion eccurs afecr ignition since $P(a) p h$ ) exceeds P(ioss) and sicady state conditions are reached at $~ 15$ kelys i.e., Nr foperation Hignition:. There is a minimu field for this size device which con provide ignition. It is about $4.0 \mathrm{~T}$ and results in an $\mathrm{Ht}$ (operation) Eurix: 
curve which is tangedt to the He (ignition) curve. Hote that bibis lould occur at about $13 \mathrm{keV}$ and $2 \times 10^{20} \mathrm{mi}^{3}$ which in tirn implics a fusion power outjut of 1200 biv. This is anjmorlant point since it means that (assuming this scaling modi? the minimuin power output associated with an ignited device of this sice is greater than 1000 Mis. A heat removal capalifity compatible with this power level would have to be installed in such a device.

The system could be operated at a higher field. in the 6.0 T case, ignition occurs at $7 \mathrm{keV}$, but the themal excursion persists to a temperature greater than $20 \mathrm{keV}$. This is the result of improved confinement at the higher field. Under these conditions the system could achieve ignition at a density less than $2 \times 10^{20} \mathrm{~m}^{\cdot 3}$. The

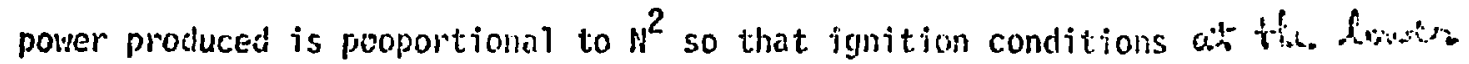

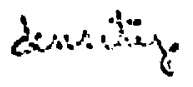
would be compatible with a power output less than 500 MW. This; of course, represcnts a low beta fysemiand is less attractive conometarly. Alternatively, a smaller size system could be used to achieve ignition under high ficld conditions. Figure ali $l$ showed that a $1 \mathrm{~m}$ plasma wis radilis may be sufficient: In this case the power output would be $630 \mathrm{HW}$ when $N=2 \times 10^{20} \mathrm{Ht}^{-3}$ and $\mathrm{T}_{i}=12 \mathrm{keV}$.

The ignition calculations above assuned a pure $\left(Z_{E F F}=1\right)$ plasma. When impurities are included, both the ignition requiroment and the system operating characteristics fohange. Figure $A$ shows tinis for the reference (Table 1) system. iman Iron is assumed to be the impunity. Due to chianced radiation losses, ignition aannot be achievcú above $Z_{\text {EFF }} \approx 1.5$. This establishas the impurity control criteria which will have to be net during the burn cycle of the devi... Note also - \{see-Fig..1)- that in the second trapped clection mode $1 / \tau=1 / 7_{\text {EFF }}$ and in the trapped ion mode Ne o. $Z_{\text {EFr }}$ so that the confincinent characteristics in

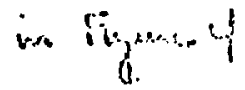


cross over after the transition into the trapped ion mode.

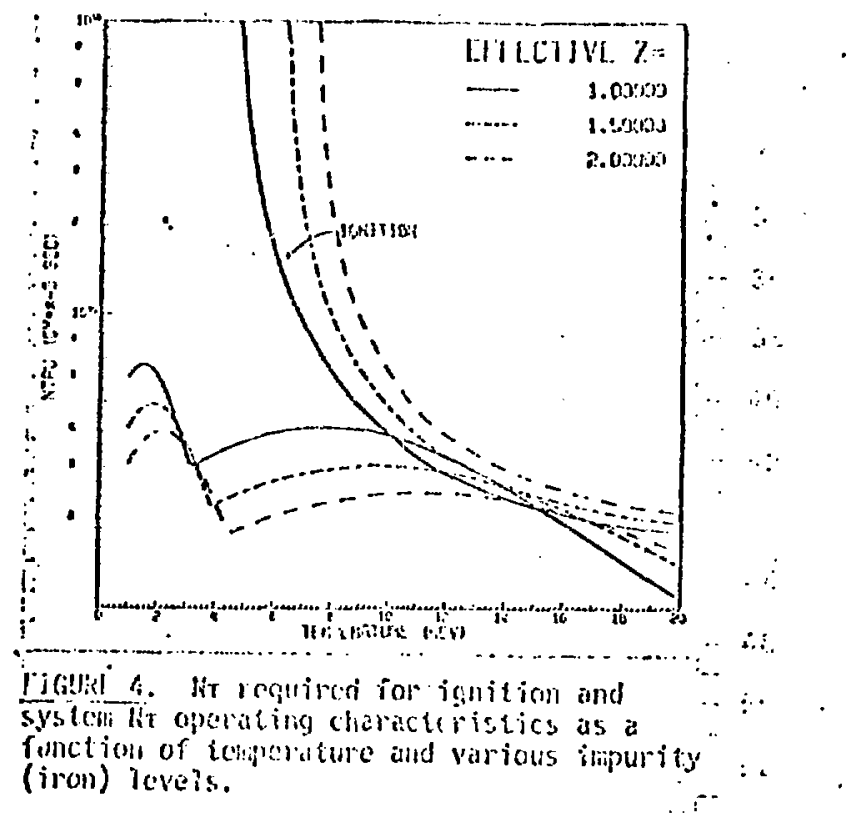

The dosired raactor plasma perfomance can be attained lat: $B_{\mathrm{T}}=4.3 \mathrm{~T}$, $N=2 \times 10^{20} \mathrm{~m}^{-3}: \mathrm{h}_{i}^{\mathrm{T}}=13 \mathrm{keV}$ prpvided that a plasma., beta of about 0.15 can be stably confined. The equilibria of such plosmas are discussed in the next section.

IV. WHD ERUILIBRIUM AND STABILITY

The value of beta in a stable toroicial plama is influenced by the plasma cross sectional shape, $(7,8)$ safety factor profile and toroidal current profile. The fonventional approach to and results of litid equilibria are discussed first and compared to those of the high beta $i^{13}$ flux-conserving tokamak (FCT) equilibitia. $(1,5)$

Under the assumptions of large aspect: io and nearlyiconcentric flux surfaces, it has been show that $\therefore=A$ is an upper limit in. $\therefore a^{\prime \prime}:$ an-uppermitit in an axisymetric couilibria. $(9,10,11)$ If $\beta_{p}$ exceeds 
N, $\therefore$

fy ifpolcidal field scparatrix would intersect ille plasma boumbary. for nearly, concenticic flux surfaces, the local values or poloidal field strength can be used to relate $q, A, B_{p}$ and $B$ as sollows,

Tis

$$
q=\frac{B_{T}}{A B} B_{P} \quad, \quad B=\frac{B_{\rho}}{q^{2} n^{2}}
$$

Thes then implies that beta is limitud to $1 / a^{2} A$, which using typical vaives for $q$ and fyjields $\beta \approx 1-5 \%$

It has been shown numerically that when these assumptions are not

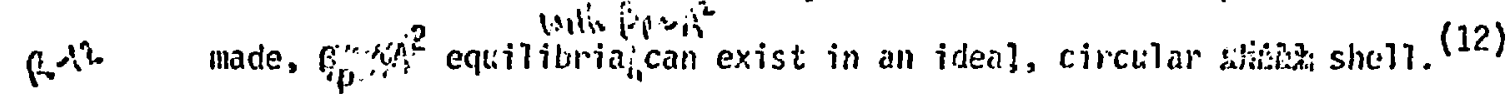

These equilibria were computed in the usual way, i.e., the pressure

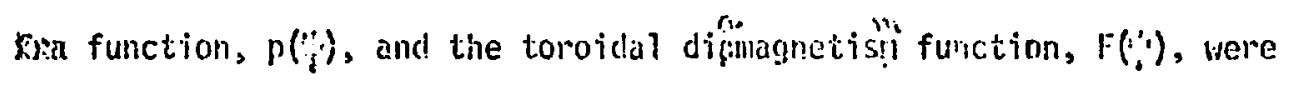
closen arbitrarily so that reasonable, bell-shaped toroidal current

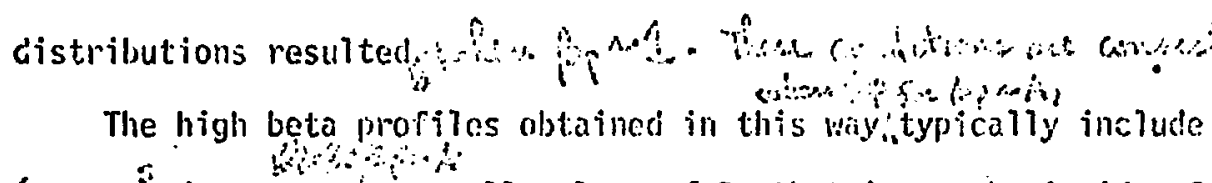
6 reverjed currents at small values of $R$, that is on the inside of the

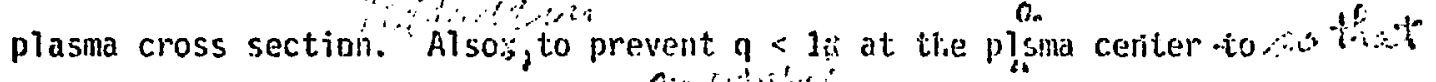
satisfy. local (liercicr ${ }^{13}$ ) stability criteria as $\beta_{p}$ is increased, it is necessary to increase $q$ at the plasma boundary. This is asompicined by increasing $B_{T}$ or decreasing the total plasnia current. Because of this, as $\beta_{p}$ is increased, $\beta$ first increases but ultimately decreases. Figure 5 shows this behavior for optimized equitibia hit D-shaped cross sections, The maximum $\beta(2.5-5.6 \%)$ depends on the shape of the currentiporite. assumed, but "occurs at $\beta_{\mathrm{p}} \sim 2.4$.

In the samie beta optimization calculations $(\eta)$ it was found that there is a limit to increasing beta by elongating the plasma. As the elongation is increased, successively more peaked current piofiles are 
required to satisfy local stability criteria. The increaseg is beta shist

obtained from the sliflit noncircularity is mo nullified as the curecint

profile becomes more peaked. The peaked profile enhances the importance

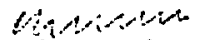

of the plasma center where the flux surfuces rema in approximately

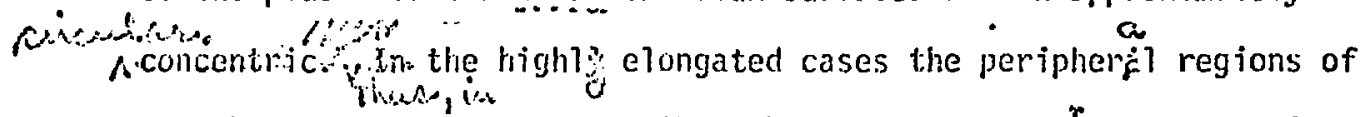
the plasma are found to contribute little to the avegrage beta. A moderate 1) 1 ing to to

elongaton of $\sim 1.6_{f i}$ provider the maximum benefit with respeci to beta within the assumptions used here.

Next the concepto of rlux-conservation and its impact on attaining

- high beta equilibria will be outlined. As described above, high belí. equilibria Nogralculations conventionally have used relatively arbitiary profiles for $f(y)$ and $r(y)$. When heating leads to a pressure excursion on a time schle which is short compared to the magnetic diffusion time, the toroidal and roloidal fluxes are frozen into the plasma. The $f(i t)$ and $F(f)$ functions winch describe Fro equilibria are inot arbitrary. Rather $f(f)$ is determined by the heating and transport processes and $F(f)$ by the requircinent that flux be conserved. Also-since, $60 \%$, seses

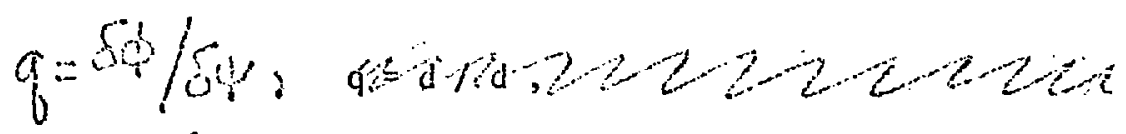

the q profile eqtablished at low beta will persist during the pressure sicustistin exciusion due to flux conservation. The beta 1 imitations observed in

F.5 Fig. 5 due to the mecessity to increase q(7imiter) to prevent $q<1$

at the plasma center should no longer occur. Numerical procedures have been developed $(5)$ to preserve $q(1)$ and $p(0)$ is increased.

A typical FCT equilibria! sequence where $q(0)=1, q(a)=4.8$,

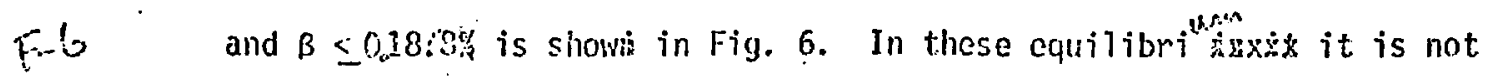




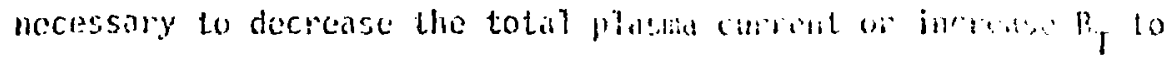

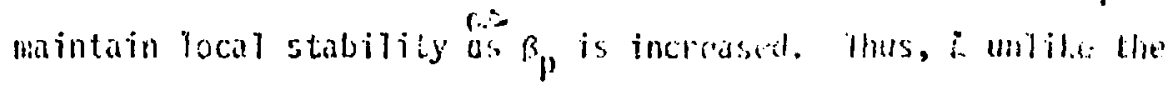

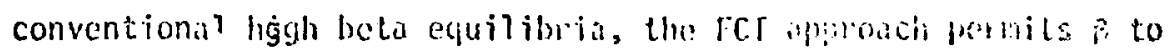
increase momolonieally with ip.

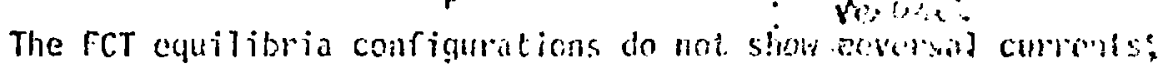

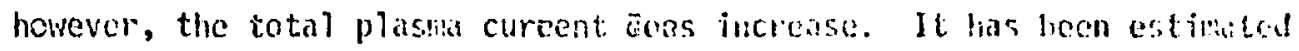
analytically ${ }^{(14)}$ that he total plasiba current scales as $p^{1 / 3}$. This has been observed namerically ${ }^{(5)}$ as mell. The increased furrut: in a high beta FCT equilibrium is produce? by diamanetic effects and does not tiin.

have to be driven by the ohnic system prinary. However, lbejpolaida?

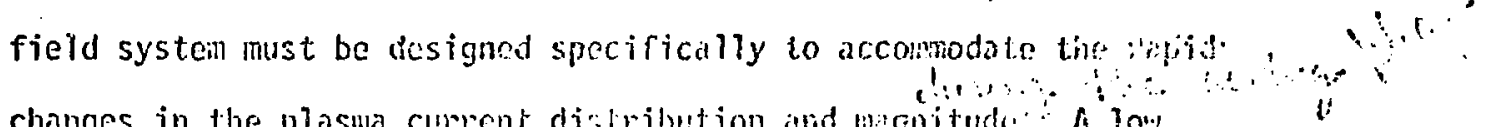
changes in the plasma corrent distribution and molitude: is ion impedence poloidal coil configuration which cân provide the neredted current wave forms during the For pulse is roguived. in! in.

Oniy local stability criteria sitisitied by $q(0) \cong 1$ have bech addressed. There is experimental cyidence bli: high beta plasmas ran operate stab?y from the beli-pinch $(15)$ and splch. (16) There is, mastis nonetheless, considerable effort required to resolve the nonlocal and more general stabiliffit quescions associated with FCT equilibria. linis work is under way. 
modest changes in the poloidal field system. This divertor configuration is "Matural" for D-shaped plasmas. The coil locations in this case are determined as described above except that the shell used is D-shaped and has a sharp tip simila. to, the geometry of a separatrix.. The resulting coil systom is shown in Fig. 7. Using these coil locations, typical FCT equilibritum $(\ddot{\beta}=0.15)$ which includes the natural divertor has been computed using the free boundary MHD code and also is shown in Fig. 7. The current required in a divertor coil is $1.54 I_{p}$ compared to $1.14 I_{p}$ for an equivalent equilibrium. without the natural divertor feature. The current level is sma11 compared to conventional divertor coil requirements, Since the coils

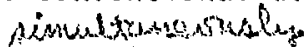

in this systemfmaintain the equilibrium and the separatrix configuration, the location of the separatrix is fixed when the plastia is centered. The difficulty of coniroliting the separatrix location show should be minimized.

Finally, the current wave forms in the coils during the pulse are of interest. The pulse is composed of start-up, ohmic heating, FCT heating, ignition excursion, burn, and shutdown phases. Start-up $(0<t \leq 1 \mathrm{~s})$ is defined as the time required for breakcown and for the plasma current to reach about $0.5 \mathrm{MA}$. During the ohmic heating phase ( $1 s \leq t \leq 2 s)$ the plasma current raises to its final value and a low beta discharge is established. The FCT heating phase ( $2 s \leq t \leq 6 s)$ is when rapid bean heating occurs and the equilibriun evolves in a way dictated by flux conservation. Ignition occurs and a therial excursion follows until the burn phase is established (10 $s \mathrm{E}$ $t \leq 30 \mathrm{~s})$. Finally, the shutdown phase $(30 \mathrm{~s} \leq t \leq 40 \mathrm{~s})$ is cntered and resuits in termination of the discharge. Figure 8 shows the 
current time histories in the plasma and the equitibrium rield and lilaseres

ohmic coil systems which are required to maintain the-fCF equilibrium during the rycle. The average beta which is also consistent with the cycle for the pre-demonstration device (cf. Tabie 1) is also shown as a function of time. This typical case does not include a natural divertor. Table 2 sumnarizes the results.

Tabie?

PARAMETERS FOR PDFD REFERERCE CYCLE

\begin{tabular}{|c|c|c|c|c|c|}
\hline$\overline{\bar{\beta}}(\%)$ & $\beta_{\text {axis }}(\%)$ & $\underline{\beta_{p}}(\%)$ & $I_{p}, 1^{7} \times I_{E F-D}(M A)$ & ${ }^{I} E F-\hat{0}^{(M A)}$ & $I_{E F-I}(M A)$ \\
\hline 0.8 & 2.7 & 0.5 & 4.1 & 2.43 & 1.94 \\
\hline 1.8 & 6.4 & 1.1 & 4.2 & 2.68 & 1.85 \\
\hline 5.7 & 17.3 & 2.6 & 4.8 & 3.60 & 1.54 \\
\hline 11.7 & 33.6 & 4.0 & 5.7 & 5.02 & 1.06 \\
\hline 14.7 & 41.2 & 4.4 & 6.1 & 5.75 & 0.82 \\
\hline
\end{tabular}

The conclusion of these analyses is that the high dersity desired' may well be accessible at mocierate magnetic field strengths (high beta) by operating in the flux-conserving mode. The poloidal ficld system required to perilit such operation is reasonable and; in faci, may faciliate impurity control as a result of its natural divertor configuration.

\section{PLASMA START-UP}

The gas breakdwon and current rise phase in a large tokamak will establish certain design criteria for the system. The parameters of special interest are voltage and current wave forms, maximum filling pressure and plasma density, volt-second consumptions, tolerable inpurity level and line radiation, wall interactions, and runaway electron flux. 
Innovative start-up schomes may be required for larije lokanaks ( $R_{0} \tilde{\sim}$ 5 meters) because high density operation may need extremely large voltages to ionize lhe gas; high runaway electron fluxes may occur; and large tokamaks are very sensitive to impurities.

Previous researcii in this area $(19-21)$ has been concened with both gas discharge physics, and atomic and moleculir physical processes. The model used in this analysis includes these processes as well as wall interactions, runaway electrons, and time-dependent impurities. These are incorporated into a set of coupled rate equations. The equations are used to compute the time-dependent average values of the density and temperature of electrons, $\mathrm{H}_{1}^{+}, \mathrm{H}_{2}^{+}, \mathrm{H}_{1}^{0}, \mathrm{H}_{2}^{\mathrm{O}}$, the nonequilibrium ionization states of oxygen, plasma current from a circuit: equation, and the runaway electron flux.

The model has been applied to the PDFD reference design (ci. Table 1). For an applied vultage of 50V/turn, which is typical of present tokamaks, and an initial $\mathrm{H}_{2}^{0}$ density of $0.2 \times 10^{20} \mathrm{~m}^{-3}$ which is five times less than is desirable for high density operation, the densitj, temperature, and plasma current stagnate at low levels. This indicates that much higher voltages are required in larger tokamaks to achieves start-up, even at relatively low filling pressures. With $N_{20}=1.0 x$ $10^{20} \mathrm{~m}^{-3}$ and $450 \mathrm{~V} /$ turn, the plasma is fulty ionized after $14 \mathrm{msec}$. However, even a sliall amount of impurities would cause line radiation at these very high densities so the plasma must be kept extremely pure.

The ionization and plasma current initis:on in large tokamaks requires very large applied voltages and low impurity levels. Ruraway electron creation nay be ar important effect. Research is required on small radius and low density start-up methods. 


\section{PILASMA HEATING}

The fundamental aspects of neutral beam heating during the plasma start-up are discussed in this section. The supplanental heating power level necessary to achieve ignition in the reference system in about $6 \mathrm{~s}$ is found to be $75 \mathrm{MH}$. This calculation is based on energy balance considurations using the final density $\left(\sim 2 \times 10^{20} \mathrm{~m}^{-3}\right)$ and does not include the problens of beam penetration into a dense plasma. High density and high impurity content make penetration into a large plasma increasingly difficult. Bean focusing, perpendicular injection, an 2

high beam energies may be necessary to overcome the penetration problem. Sma17 radius start-up and low density start-iij may provide ocher means to solve the problelli. Here the concept of low density start-up, which has previously been suggested $(22,23)$ is outlined.

Bean deposition can be characterized by the function $H(\bar{r})$ which was first introduced by Rome et al. ${ }^{(24)} H(r)$ is a geonletric measur: of the deposited fast ion number density profile which resuits from injection. It is desirable to have the beam deposition peaked in ths. central region of the plasma for maximum heating efficiency. In these caiculations a deuteron bean, $30 \mathrm{~cm}$ in diameter, is assumed to be injected into a $7_{\text {EFF }}=1$ plasma.

Figure 9 shows the deposition profiles for several different beam energies. In these cases injection is nearly perpendicular $\left(16^{\circ}\right.$ from perpendicular to prevent ripple trapping of the fast ions), and the density profile is assumed to be $n=3 \times 10^{20}\left(1-(r / a)^{2}\right) m^{-3}$. Adequate penetration can be achieved in this way if a beam energy of $\sim 250 \mathrm{keV}$ can be made available. Impurity effects dictate an every higher energy.

High density and temperature are required at the ignition point where the beams are no longer needed to sustain the posma energetically. 
It may be possible to establish the temperature conditions at low density, increase the fueling rate to build up the necessary density white contiauing injection, and tolcrate the less favorable injection profiles which wi?l occur near the end of the heating power. Figure 10 shows $H(r)$ for 150 keV tangential injection into average densities of $7.5,10$, and $20 \times 10^{19} \mathrm{~m}^{-3}$. The injection deposition profile is favorably peaked when $N=7.5 \times 10^{19} \mathrm{~cm}^{-3}$, is relatively flat for $N=1 \times 10^{20} \mathrm{~m}^{-3}$ and becomes peaked at $\mathrm{r} / \mathrm{a}=0.75$ when $\mathrm{N}=2 \times 10^{20} \mathrm{~m}^{-3}$. Therefore, heating efficiency will decrease when $\mathrm{N}>1 \times 10^{20} \mathrm{~m}^{-3}$, but if this part of the heating cycle occurs over a time on the order of ais energy confinement time, thejess efficient heating process may well be tölerable.

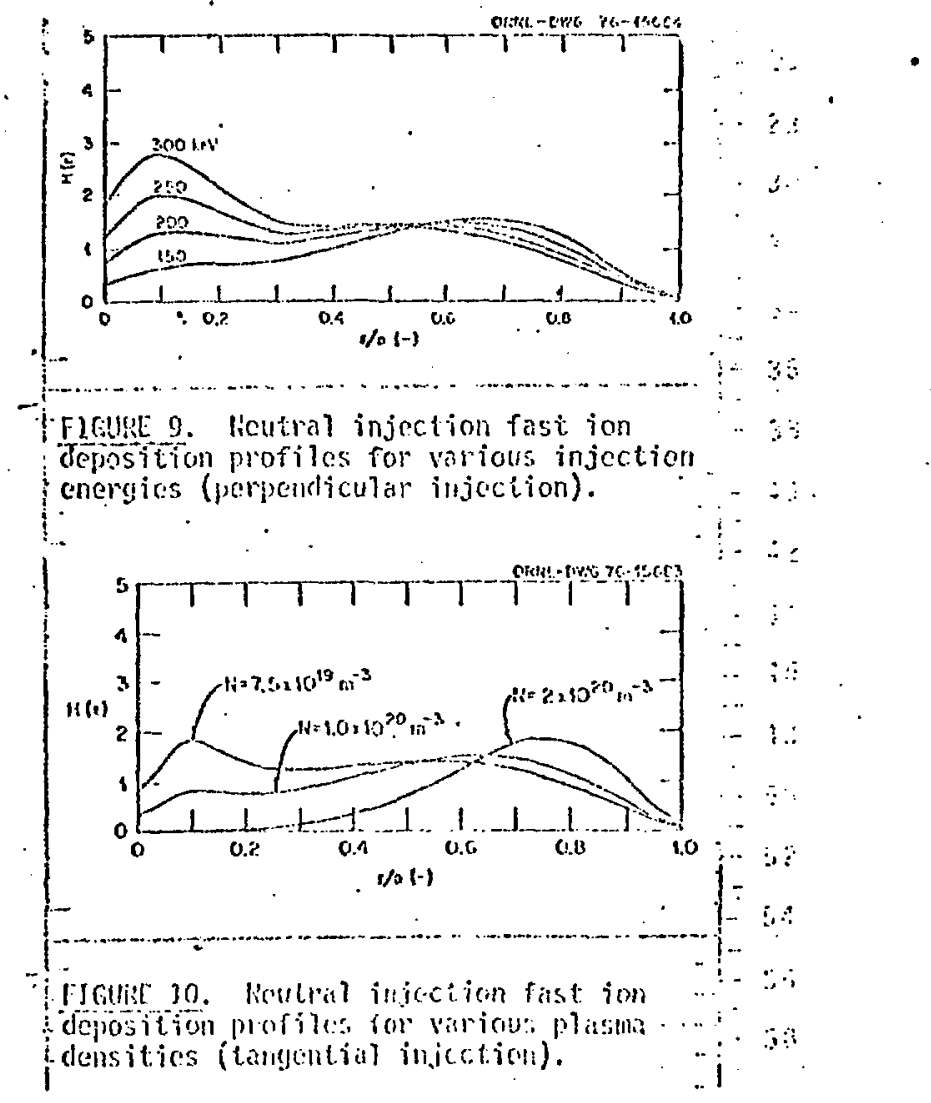


Figures 11 and 12 show the tilite-dependent density and power histories during heating. Initially $\mathrm{N}=7.5 \times 10^{19} \mathrm{~m}^{-3}, \mathrm{~T}=100 \mathrm{cV}$, and $P_{\text {beam }}=75 \mathrm{kl}$. At $t=2 \mathrm{~s}, \mathrm{~T}_{\mathrm{i}}=12 \mathrm{kcV}$; and the fueling rate is increased to begin the density buildup phase. The plasma ignites and beun injection is terminated afier $t=4.4 \mathrm{~s}$. Density buildup occurs over a period of $2.4 \mathrm{~s}$, and the average energy confinement time during this phase is $\tau_{E}$ \& $1.5 \mathrm{~s}$. Energetically this scenario is feasible since 75 Min is sufficient to heat the plasma to ignition at full density.
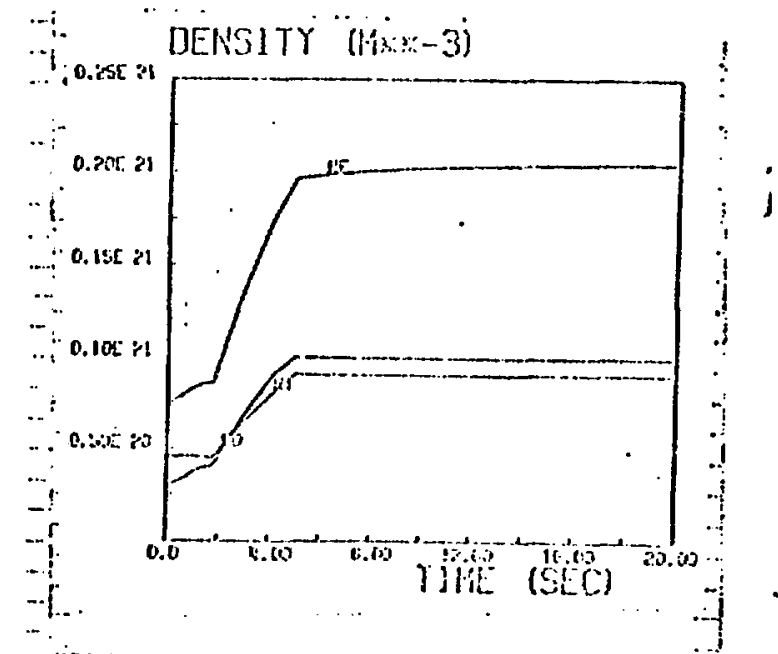

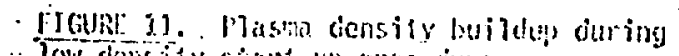

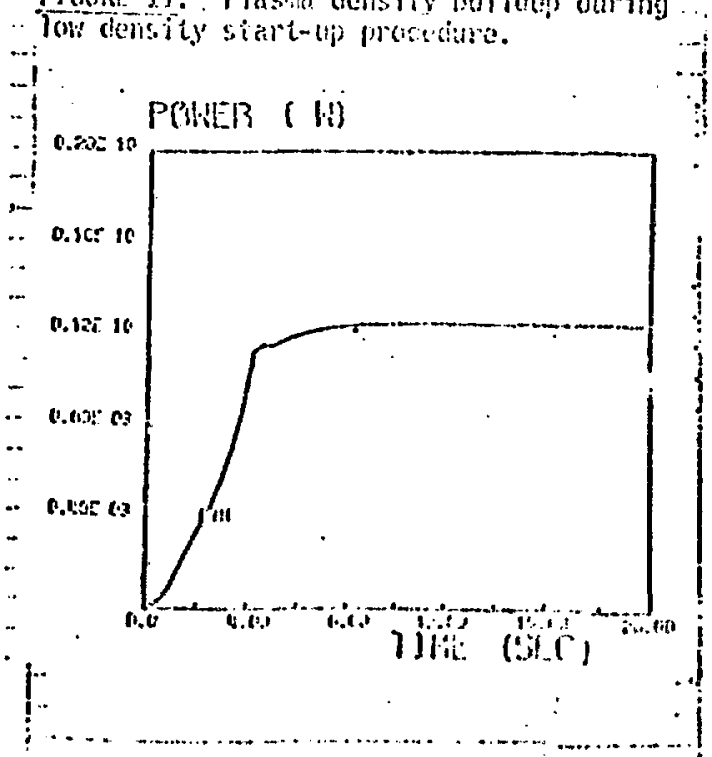

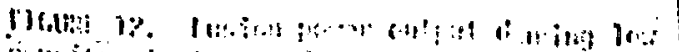

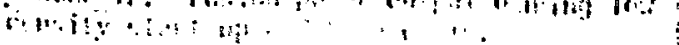


In fact, more detailed studies of the iow-densily apprach using a colpled beall deposition-spatially sepencent trinsport calculation are necessary to optinize the start-up procedure. A1so, as the flux surfaces shift when high beta is attaincd, beam penetration should iniprove.

\section{CONCLUSIONS}

There are incentives for high density operation in a tokanak reactor. Several features of a PDFD which will demoristrate the feasibility of attaining such operation in a flux-conserving tokamak were described. Other key aspects such as fueling, impur'ity control. and the effects of magnetic field ripple were not included here. Suitable high beta equilibria were found and a poloidal field system design compatible with the equilibria was developed. The natural divertor configuration inherent in the system led to including a poloidal divertor in the PDFD. The start-up analyses showed that further innovations die required unless very large voltages are applied to achieve breakdom and to establish the plasma current. Neutral beam energies of $\approx 300 \mathrm{keV}$ were found to be necessary when the plasma is heated under full bore and fuil density conditions. A low density siart-up procedure was outlined which, if feasible, suggests that beams with energies similar to those being developed for TFTR may be adequate to achicve ignition in the PDFD. Successful operation of a PDFD of this type will lead to high power density, high beta fusion reactors of reduced physical size. These features, in turn, enhance the rossibility of attaining economic viability in the tokamak. 


\section{ACKMOHLEUCILATS}

Direct contributions to this paper from Drs. S. E. Attenberger, J. D. Callen, F. B. Marcus, A. T. Mense, Y-K. M. Peng, J. A. Rome, and N. A. Uckan were greatly appreciated. 